\title{
Experimental Study of Clarification of Vortex Structure by Changing Disk Acceleration Time
}

\author{
Hiroyuki Furukawa, Akihiro Wada, Takashi Watanabe \\ Department of Mechanical Engineering, Meijo University, Nagoya, Japan \\ Email: furukawa@meijo-u.ac.jp
}

How to cite this paper: Furukawa, H., Wada, A. and Watanabe, T. (2017) Experimental Study of Clarification of Vortex Structure by Changing Disk Acceleration Time. World Journal of Mechanics, 7, 185194.

https://doi.org/10.4236/wjm.2017.78017

Received: June 30, 2017

Accepted: July 28, 2017

Published: July 31, 2017

Copyright $\odot 2017$ by authors and Scientific Research Publishing Inc. This work is licensed under the Creative Commons Attribution International License (CC BY 4.0).

http://creativecommons.org/licenses/by/4.0/

\begin{abstract}
Disks with two different dimensions were used to clarify the differences in final vortex structures generated by the change in disk acceleration time. The experiment results and calculated results of vortex structures match when the disk thickness is $20 \mathrm{~mm}$ and the Reynolds number is 5000 - 15000. Also, they match when the disk thickness is $30 \mathrm{~mm}$ with a Reynolds number from 3000 5000 and 9000 - 20000. Even when the size of the disk and the Reynolds number are the same, the final vortex structures can be different due to differences in the disk acceleration time.
\end{abstract}

\section{Keywords}

Rotating Disk, Flow Instability, Bifurcation, EFD and CFD

\section{Introduction}

The flow brought about by a rotating object within a container is often seen in fluid machines which provide/get energy to fluids via the rotation of vaned wheels such as centrifugal pumps and turbines. Many related studies have been conducted by Bödewadt et al. [1]. If the gap between both disks is large, the flow has a separate boundary layer, as studied by Batchelor [2]. However, in many studies thus far, rotating disks have simply been used as something to provide peripheral velocity and the shape has not been taken into consideration much. However, it is known that the radial gap has a significant impact on the flow between the rotating disk and fixed disk on the base of the container [3]. The impact of this gap in the radial direction on the flow between the base of the container and the rotating disk is called as the edge effect [4].

Rotating flows can be found in fluid machinery and chemical reactors and they are examined to improve their performance [5]. When the flow around a 
rotating disk in a cylindrical casing represents a model of the flow in hard disk drives and stirrers, the radial clearance between the disk tip and the side wall of the casing is inevitable. Schouveiler et al. [6] implied that the radial clearance bores new spiral flows. Al-Shannag et al. [7] numerically examined the flow around corotating two disks connected by a central hub and showed the effect of the velocity fluctuation in the radial clearance on the interdisk flow. Hendriks [8] predicted a more realistic flow in a hard disk drive. He obtained Taylor vortices formed between the rotating disk and the side wall of the casing and found the jet-like radially outward flow on a rotating disk.

In research conducted thus far, rotating disks of different shapes are used to change the gap within cylindrical containers and experiments have been conducted in respect of the impact that the gap in the radial direction has on the disk rotor in the container and, as a result, from the difference in disk dimensions, fluid movement phases that changes with each disk have been confirmed. Hence, in this study, experiments have been conducted to clarify the edge effect using disks with different dimensions by focusing on the edge effect. The transition scenario for the complex flow and the geometric effect changing the acceleration time has not been well clarified. The purpose of this study is to clarify the vortex structure by changing disk acceleration time.

\section{Experiment Device and Its Procedure}

\subsection{Experiment Device}

Figure 1 shows the main component of the experiment device. The cylindrical container containing the test fluid is constructed of two fixed disks at the top and the bottom and a cylindrical frame with an internal diameter of $142.0 \mathrm{~mm}$ and a thickness of $40.0 \mathrm{~mm}$. The fixed disk and the cylindrical frame are both made of acrylic resin materials. The rotating disks are attached to the rotating axes and the axis diameter is $20.0 \mathrm{~mm}$. So that the flow between the disks, which

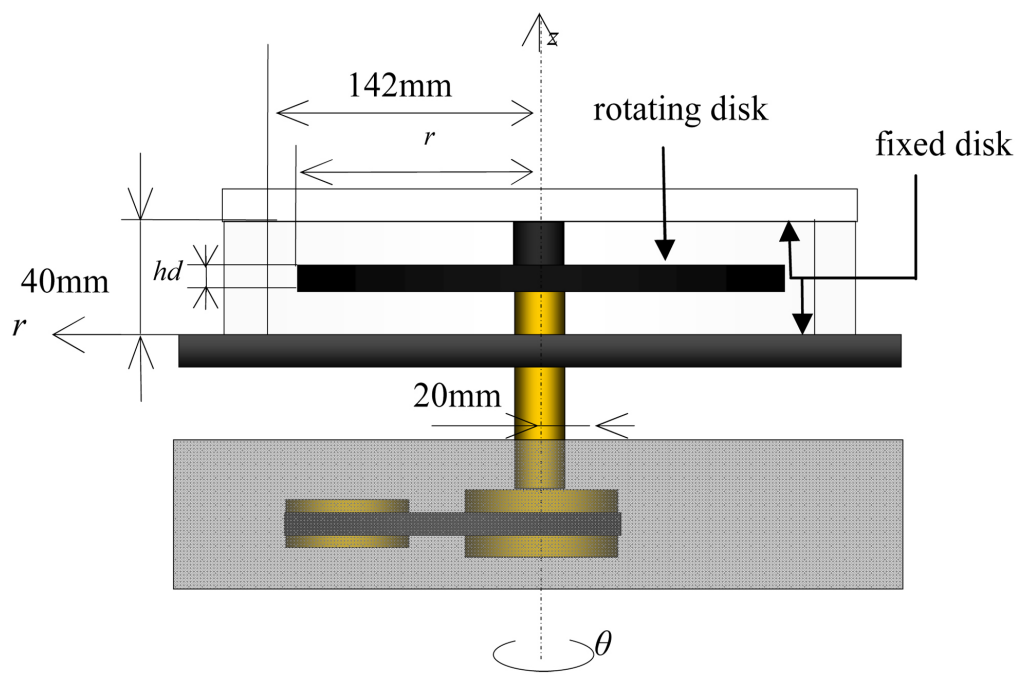

Figure 1. The main part of the experimental device. 
is the flow between the fixed disk and the rotating disk, is such that the space in the container with rotating disk is symmetrical, the disk joining part has the same diameter as the rotating axis of $20.0 \mathrm{~mm}$. The material of the disk is duralumin and the whole thing is coated with matte black. The dimensions of the rotating disk fixed in the container are as follows. Disk: Radius $r=127.0 \mathrm{~mm}$, thickness $h d=30.0 \mathrm{~mm}$.

\subsection{Surroundings of Experimental Device}

The experiment devices used were an acrylic casing (Sanwa Kiki manufacturing) Xenon slit light source (500W, KS2000-30, Katou Mitsuken), an inverter (Mitsubishi Electrics), a control box (Sanwa Kiki manufacturing), a digital tachometer (Mitsubishi Electrics), and the main part of the experimental device, which was attached to them. Filming utilized a digital video camera (SONY HDRCX560V) which has an effective pixel count of 6,140,000 (16:9) and, in this research, the filming was done with an average bit rate of $28 \mathrm{Mbps}$ with a resolution $1920 \times 1080$ pixels and framerate of $60 \mathrm{fps}$. The recorded image can be digitally processed via a computer. A slit light source was placed right next to the cylindrical container so that the irradiation position would be horizontal and the experiment device was placed in a dark room to avoid light from the outside. Moreover, to achieve the desired number of rotations, the motor rotation was controlled with an inverter and the setting of the disk acceleration time was conducted with a MELSOFT series GX Works II (Mitsubishi Electrics) and the number of rotations of the axis was confirmed using a digital tachometer.

The test fluid uses Newton liquid in which distilled water and glycerin are mixed together well at specified mass ratios. This research used the ratio 3:2 of water to glycerin in the test fluid. To obtain the kinetic viscosity $v$, a specific gravity meter (Nihon Keiryoki Kogyo K. K) was used. Moreover, viscosity $\mu$ was measured used an SV type viscosity meter (SV-10 KK A \& D).

The three-dimensional flow inside the container is visualized on a two-dimensional plane using aluminum powder. The visualization using aluminum powder is done by mixing aluminum powder, which has been put into a sieve with a lattice width of $20 \mu \mathrm{m}$, with the test fluid. The amount of aluminum powder mixed in is $0.1 \mathrm{~g}$ for $2.5 \mathrm{l}$ of test fluid. Moreover, to prevent aluminum powder from floating due to surface tension of the test fluid at this point, 1 - 2 droplets of household neutral detergent are mixed in.

\subsection{Structure of Vortex Appearing in the Gap in the Radial Direction}

The Reynolds number $\operatorname{Re}=\omega r_{d}^{2} / v$ was used as an index of the flow. $\omega$ is the angular velocity of the rotating disk and is calculated from the number of disk rotations $N$. All rotating disks rotate counterclockwise. Rotating speed of the disk corresponding to the target Reynolds number is achieved from the initial stationary state by setting a disk accelerating time and matching that time. Then 
after achieving the rotation velocity target, then the final vortex structure is visually confirmed after one minute 30 seconds.

On this occasion, two types of disks $-20 \mathrm{~mm}$ and $30 \mathrm{~mm}$-are used. Moreover, disk acceleration times are $1 \mathrm{~s}$ and $30 \mathrm{~s}$ with a Reynolds number from 3000 20000 at 1000 intervals. It is thought that there are 4 types of vortex structures appearing in the gaps between the axes. The four types are polygonal, ring, positive progressing spiral, and negative progressing spiral.

\subsection{Change in Acceleration Time}

In past experiments, it was impossible to set the Reynolds number within a stipulated time. In this experiment, the disk acceleration time was changed using a control box and MELSOFT series GX Works II (Mitsubishi Electrics).

An example of the change in the disk acceleration time is shown in Figure 2. Between $t=0 \mathrm{~s}$ to $t=5 \mathrm{~s}$, if angular velocity corresponding to a Reynolds number of $\operatorname{Re}=2000$ is set to be reached in $t=5 \mathrm{~s}$, the Reynolds number can be increased at a fixed angular acceleration. Moreover, in a similar way, the angular velocity is increased from $t=10 \mathrm{~s}$ to $t=15 \mathrm{~s}$ and between $t=25 \mathrm{~s}$ and $t=30 \mathrm{~s}$. In this class, the change in the angular acceleration occurs only once from $t=0 \mathrm{~s}$ to $t=1 \mathrm{~s}$ or $t=0 \mathrm{~s}$ to $t=30 \mathrm{~s}$.

\subsection{Parameters}

Moreover, in the actual experiment, to obtain the desired Reynolds number Re, the required rotational velocity was derived from viscosity and specific gravity. The final rotational velocity of the disk is set in respect of this derived result.

The viscosity of the test fluid is taken to be $\mu(\mathrm{mPa} \cdot \mathrm{s})$, specific gravity $s$ and the number of disk rotations, $N(\mathrm{rpm})$. The representative velocity is taken to be $V(\mathrm{~m} / \mathrm{s})$, representative length $r(\mathrm{~m})$, and kinetic viscosity, $v\left(\mathrm{~m}^{2} / \mathrm{s}\right)$.

The required number of rotations was derived from the following equation.

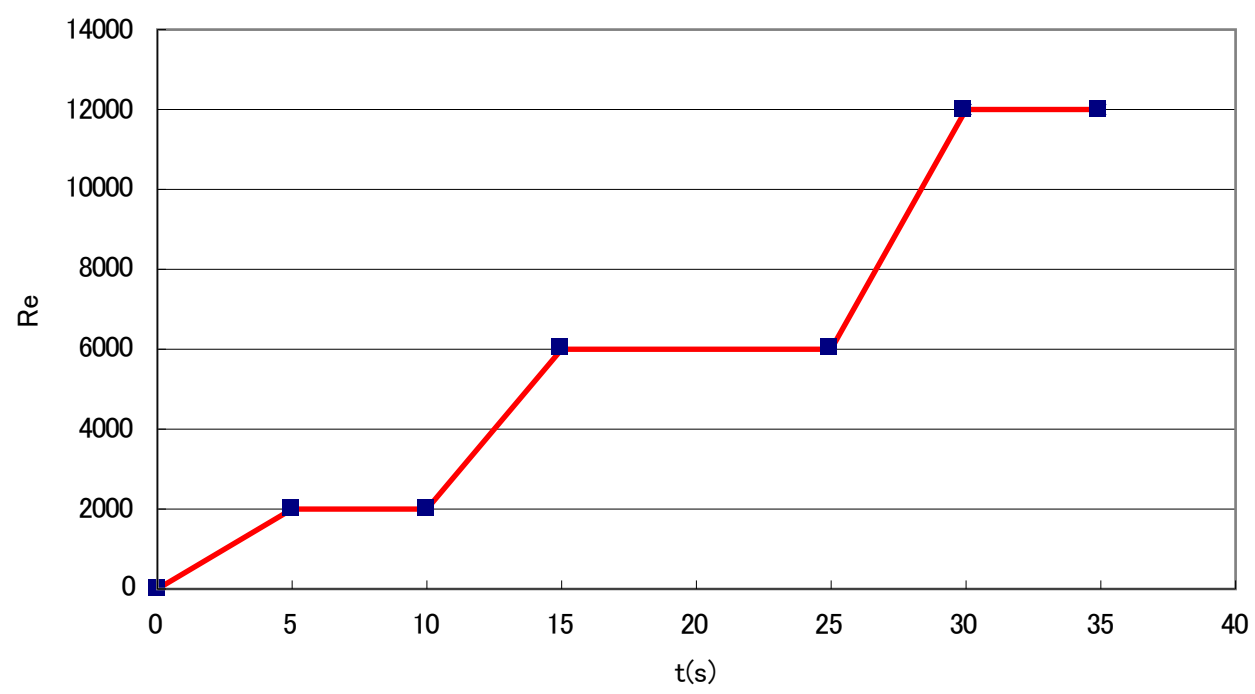

Figure 2. Example of programme of acceleration time. 


$$
\begin{gathered}
\operatorname{Re}=\frac{\omega}{v} \times r^{2}=\frac{V \times r \times 10^{-3}}{\frac{\frac{\mu}{s} \times 10^{-3}}{s \times 10^{-3}}}=\frac{\left(r \times 10^{-3}\right)^{2} \times \omega}{\frac{\mu}{s^{2}} \times\left(10^{-3}\right)^{2}} \\
\omega=\operatorname{Re} \times \frac{\mu}{(r s)^{2}}(\mathrm{rad} / \mathrm{s}) \\
N=\frac{60}{2 \pi} \times \frac{\mu}{(r s)^{2}} \times \operatorname{Re}=\frac{30 \mu}{\pi(r s)^{2}} \times \operatorname{Re}(\mathrm{rpm})
\end{gathered}
$$

\section{Results}

\subsection{Numerical Results}

The numerically calculated values for vortex structure when the disk acceleration time is $1 \mathrm{~s}$ are compared against the experimental results. Below, Figure 3

Disk thickness hd[mm]

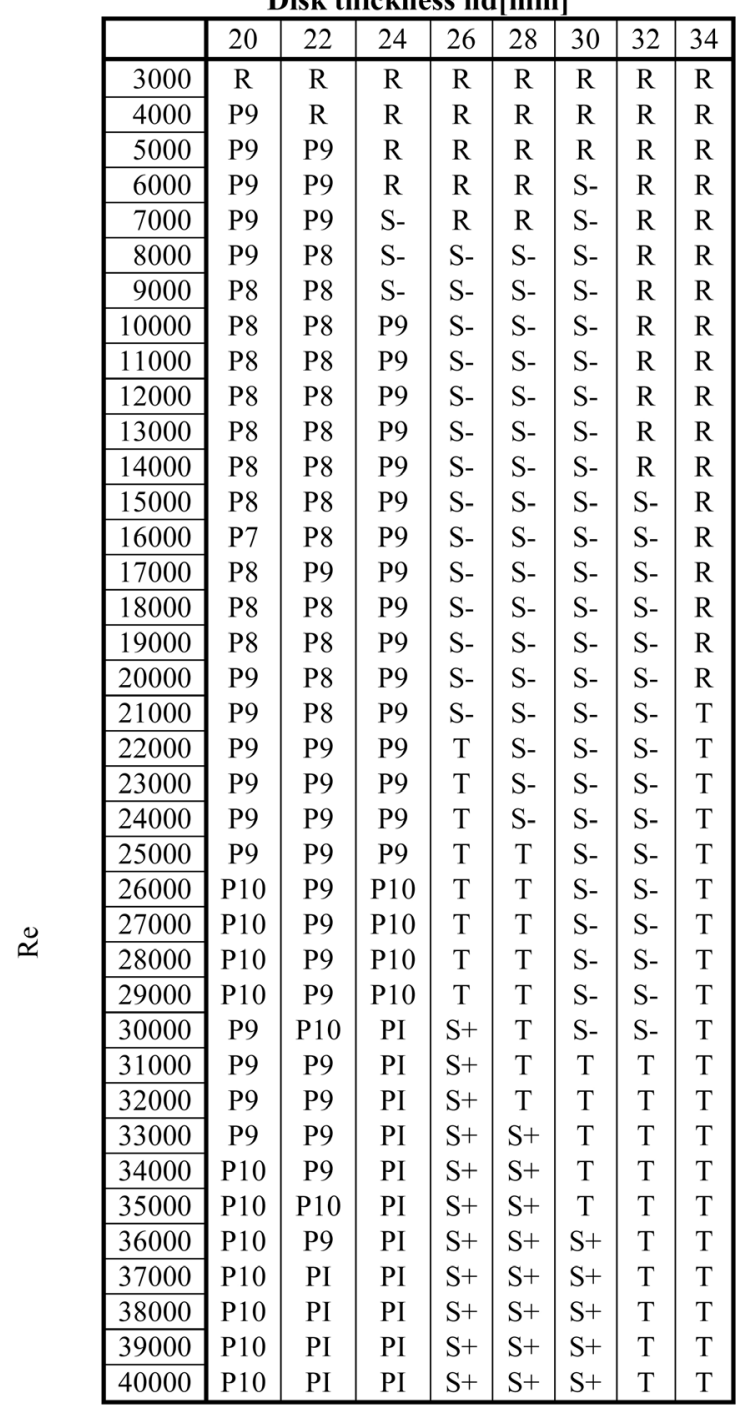

Figure 3. Numerical calculation results. 
shows the numerically calculated results. This figure plots the Reynolds number on the vertical axis and the thickness of the disk on the horizontal axis. $t_{\mathrm{s}}$ represents the disk acceleration time and $h$ the thickness of the disk. Furthermore, the polygonal vortex, ring vortex, and negatively progressing spiral vortex are abbreviated as $\mathrm{P}, \mathrm{R}$, and $\mathrm{S}-$, respectively.

\subsection{Structure of Vortex Appearing in the Gap in a Radial Direction}

The structure of the vortex appearing in the radial gaps is shown below. Figure 4 shows an enlarged image of the tip of the radial gap of the container and the disk. The grey part is the disk. The vortex appearing on the disk side shows various shapes depending on the Reynolds number, disk thickness, and disk acceleration time.

Disk vortex structures expected to appear are shown in Figure 5. These are results calculated, and show the types of vortex structures expected to appear in respect of each disk thickness $h d$ and Reynolds number Re. The figure below shows the disk acceleration time as $t_{s}=0(\mathrm{~s})$.

Next, a ring vortex appears at a Reynolds number of 3000 when the disk thickness is $20 \mathrm{~mm}$. A polygonal vortex appears at a Reynolds number of 4000 20000. A ring vortex appears at a Reynolds number of 3000 - 5000 when the disk

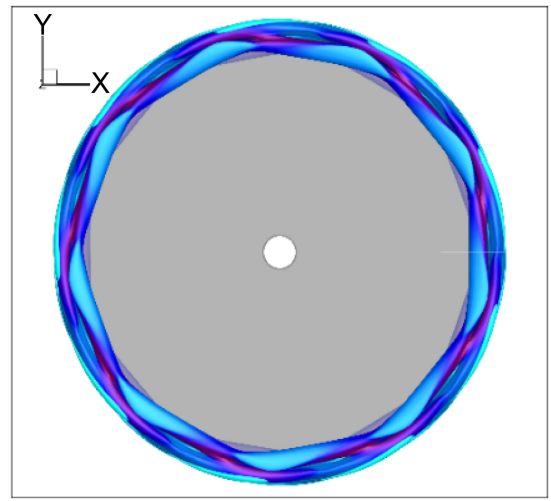

(a)

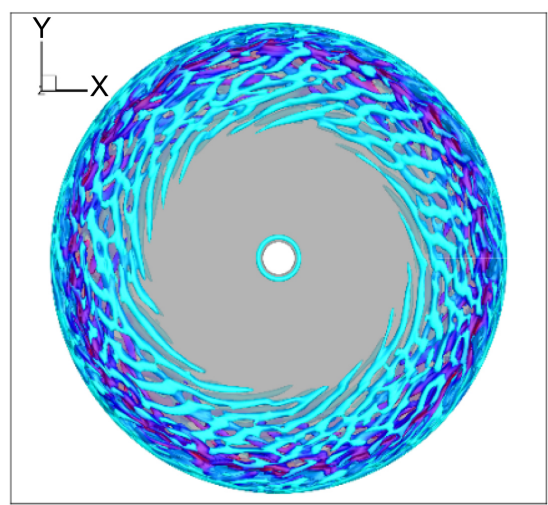

(c)

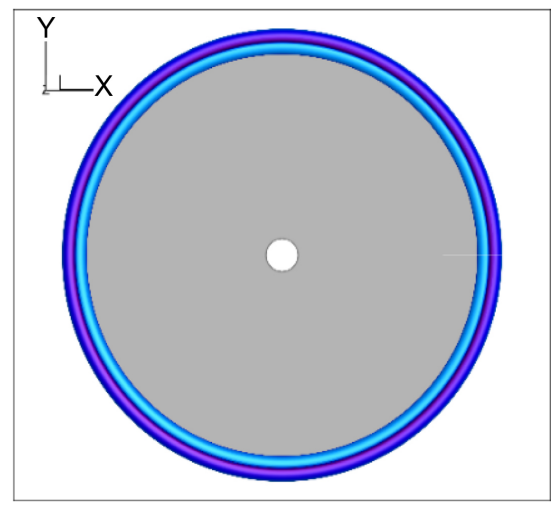

(b)

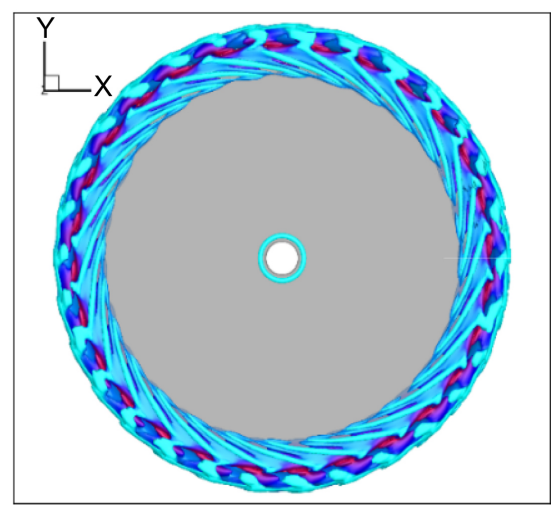

(d)

Figure 4. Structure of main vortices. (a) Polygonal vortex. (b) Ring vortex. (c) Positive travelling wave spiral vortex. (d) Negative travelling wave spiral vortex. 


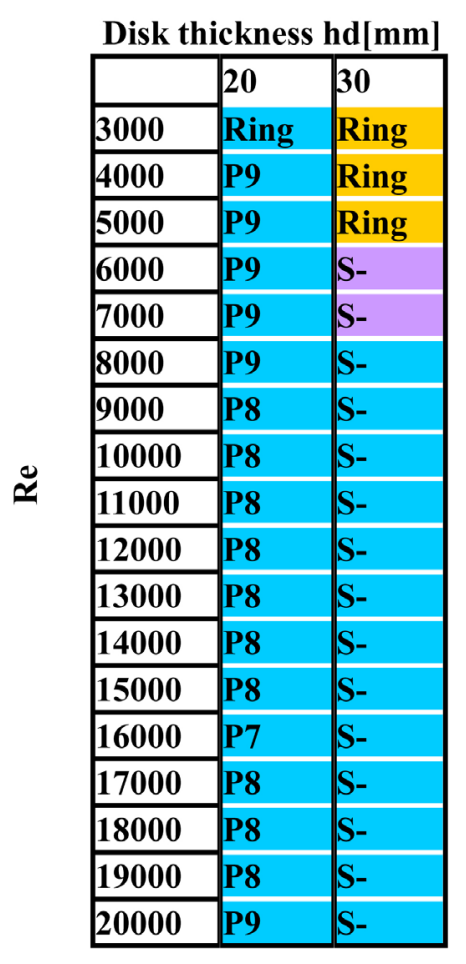

Figure 5. Results of numerical calculation for the final structure of the vortex.

thickness is $30 \mathrm{~mm}$. A negatively progressing wave spiral vortex appears at a Reynolds number of 6000 - 20000. Furthermore, the vortex structures of polygonal vortex and negatively progressing spiral vortex are abbreviated as P and S-, respectively.

\subsection{Experimental Results When the Disk Acceleration Times Are Different}

The vortex structures that appeared when the disk thickness was $20.0 \mathrm{~mm}$ and $30.0 \mathrm{~mm}$ with a disk acceleration time of $1 \mathrm{~s}$ and $30 \mathrm{~s}$ are shown in Table 1.

Different results were shown in the table when the disk thickness was $30 \mathrm{~mm}$ when the Reynolds number was 7000 - 10000. Furthermore, vortex structures which could not be clearly determined visually or as a polygon, ring, negatively progressing spiral-as $\mathrm{p}, \mathrm{r}$, s- were marked as undeterminable.

\section{Comparison between Experimental and Numerical Results}

\subsection{Vortex Structure}

The vortex structure was filmed across the $r-\theta$ cross-section. Part of the still images is shown from Figures 6-8.

Figure 6 shows that the final vortex structure seen when the disk thickness is $20.0 \mathrm{~mm}$, the Reynolds number is 10,000 , and the disk acceleration time is $1 \mathrm{~s}$ is a 
Table 1. Comparison of experimental result when the disk acceleration time is $1 \mathrm{~s}$ with when $30 \mathrm{~s}$.

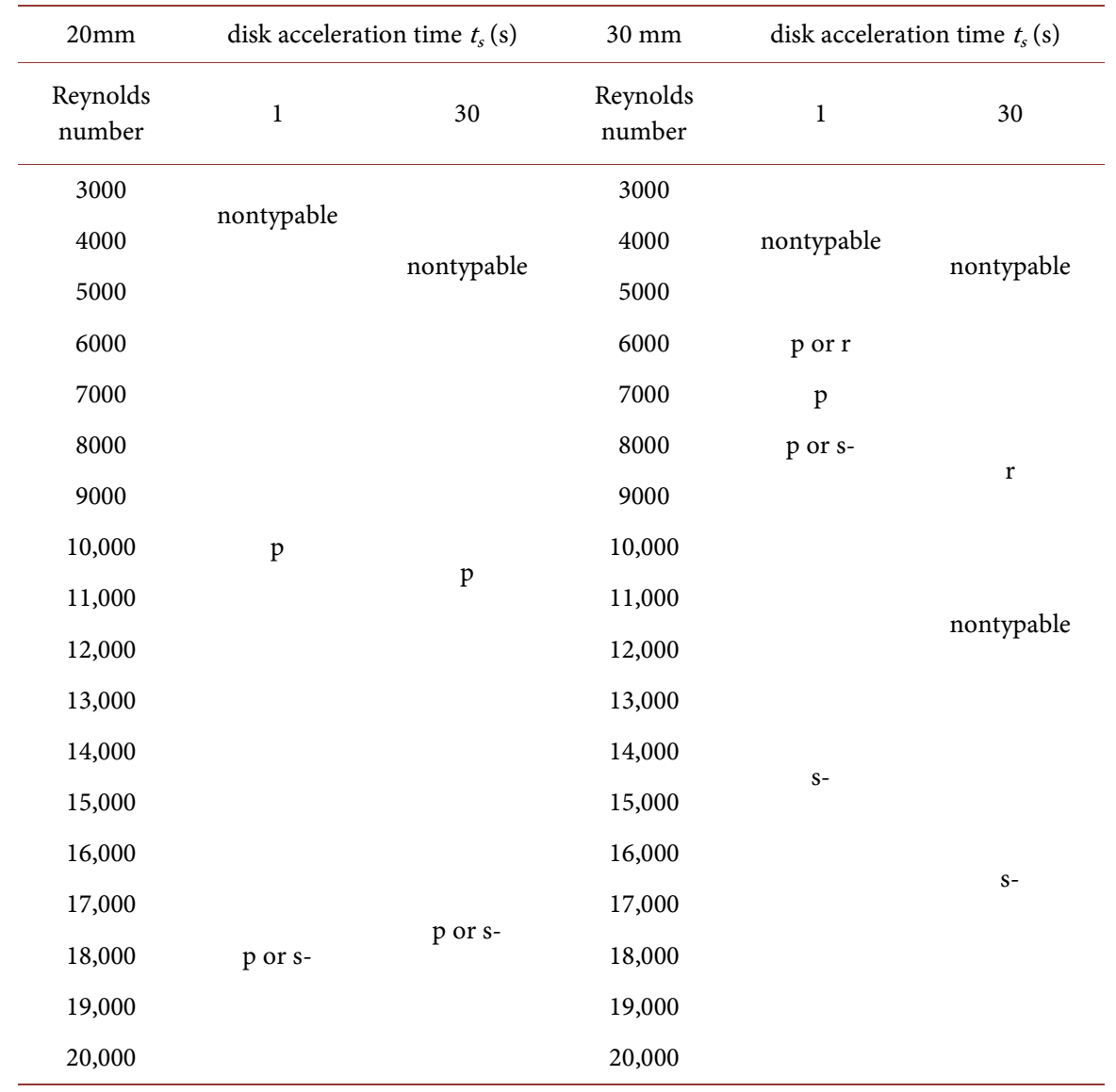

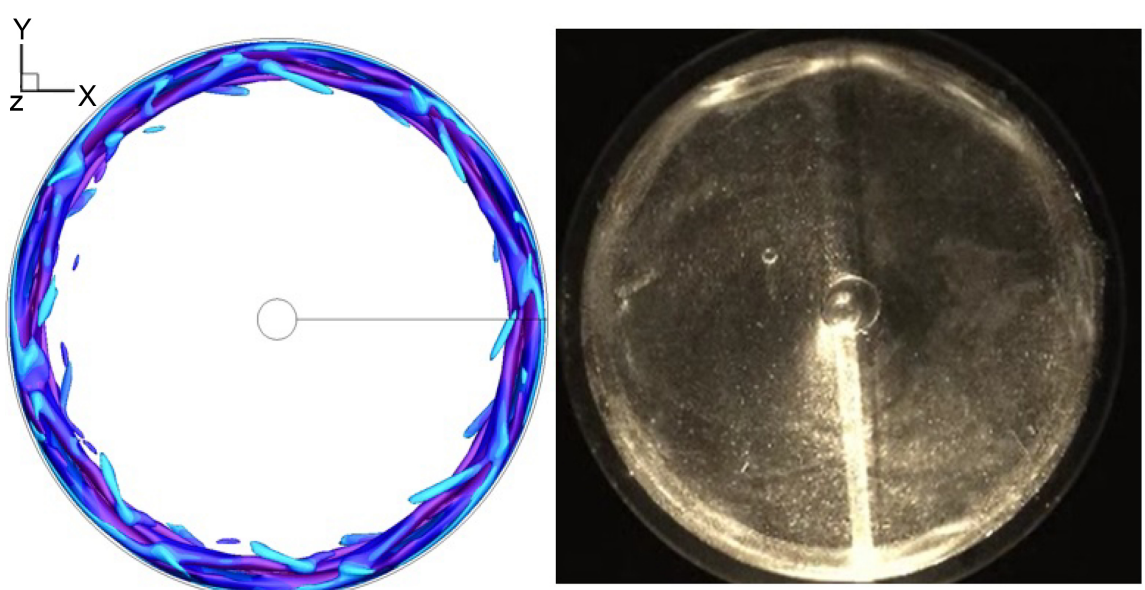

Figure 6. Polygonal vortex $\left(h_{d}=20.0 \mathrm{~mm}, \mathrm{Re}=10,000, t_{s}=1 \mathrm{~s}\right)$.

polygonal vortex. Similarly, Figure 7 shows that the final vortex structure seen when the disk thickness is $30.0 \mathrm{~mm}$, the Reynolds number is 15,000 , and the disk acceleration time is $30 \mathrm{~s}$ is a negatively progressing spiral vortex. Figure 8 shows that the final vortex structure seen when the disk thickness is $30.0 \mathrm{~mm}$, the Reynolds number is 10,000 , and the disk acceleration time is $30 \mathrm{~s}$ is a ring vortex. 

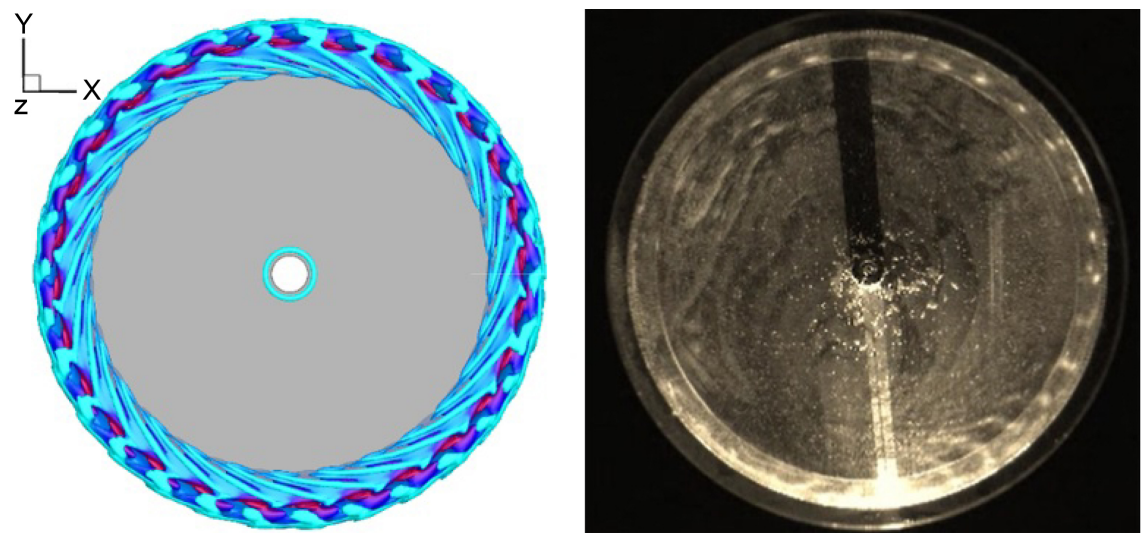

Figure 7. Spiral vortex of negative progressive wave $\left(h_{d}=30.0 \mathrm{~mm}, \operatorname{Re}=15,000, t_{s}=30 \mathrm{~s}\right)$.
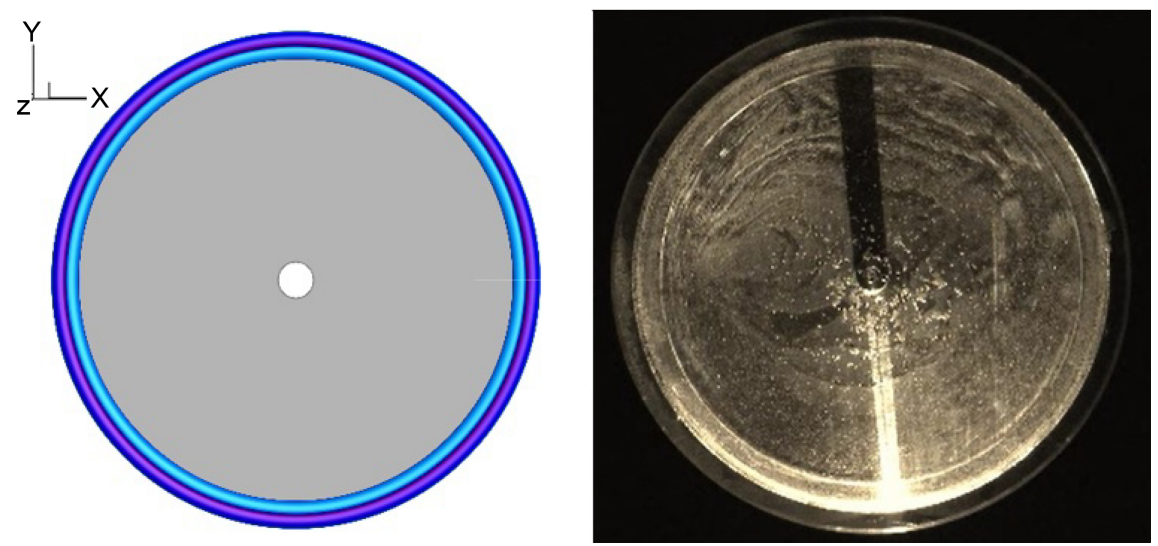

Figure 8. Ring vortex $\left(h_{d}=30.0 \mathrm{~mm}, \mathrm{Re}=10,000, t_{s}=30 \mathrm{~s}\right)$.

\subsection{Comparison of Reynolds Number}

Results comparing the final vortex structures obtained by experiment and by numerical calculation results discretized using the difference method with the three-dimensional unsteady compressible Navier-Stokes equation are shown in Table 2. There was a comparison with the situation when the disk acceleration time is $1 \mathrm{~s}$ for all experiment conditions conducted on this occasion.

From the table, it can be said that the numerically calculated results and experiment results match when the disk thickness is $20 \mathrm{~mm}$ with a Reynolds number of $5000-1500$ and when the disk thickness is $30 \mathrm{~mm}$ with a Reynolds number of $9000-20000$.

\section{Conclusions}

Disks with two different dimensions were used to clarify the differences in final vortex structures generated by the change in disk acceleration time and the following results were obtained based on visualization experiments and analysis results.

1) The experiment results and calculated results of vortex structures match when the disk thickness is $20 \mathrm{~mm}$ and the Reynolds number is $5000-15000$. Also, they match when the disk thickness is $30 \mathrm{~mm}$ with a Reynolds number from 
Table 2. Comparison of experimental result with calculated result.

\begin{tabular}{ccccc}
\hline $\begin{array}{c}\text { Disk } \\
\text { acceleration } \\
\text { time } t_{s}(\mathrm{~S})\end{array}$ & $\begin{array}{c}\text { Disk } \\
\text { thickness } \\
h d(\mathrm{~mm})\end{array}$ & Reynolds number & $\begin{array}{c}\text { Experimental } \\
\text { result }\end{array}$ & $\begin{array}{c}\text { Calculated } \\
\text { result }\end{array}$ \\
\hline 20 & $5000-15,000$ & $\mathrm{p}$ & $\mathrm{p}$ \\
$16000-20,000$ & $\mathrm{~s}-$ & $\mathrm{r}$ \\
1 & $3000-5000$ & $\mathrm{r}$ & $\mathrm{s}-$ \\
& 6000 & r or p & \\
\hline
\end{tabular}

$3000-5000$ and $9000-20000$.

2) Even when the size of the disk and the Reynolds number are the same, the final vortex structures can be different due to differences in the disk acceleration time.

\section{Acknowledgements}

This research was supported by the research grant from the Nitto Foundation. We appreciate good comments from reviewers.

\section{References}

[1] Bödewadt, U.T. (1940) Die Drehströmung über festem Grunde. Zeitschrift für Angewandte Mathematik und Mechanik, 20, 241-253. https://doi.org/10.1002/zamm.19400200502

[2] Batchelor, G.K. (1951) Note on a class of solutions of the Navier-Stokes equations representing steady rotationally symmetric flow. The Quarterly Journal of Mechanics and Applied Mathematics, 4, 29-41. https://doi.org/10.1093/qjmam/4.1.29

[3] Serre, E., Crespo Del Arco, E. and Bontoux, P. (2001) Annular and spiral patterns in flows between rotating and stationary disk. Journal of Fluid Mechanics, 434, 65-68. https://doi.org/10.1017/S0022112001003494

[4] Tsutsui, M. (2004) Research Relating to Transition Pattern of Rotating Disk Flow in a Container. The Japan Society of Mechanical Engineers Fluid Engineering Lecture Series Thesis Collection, North Kyushu, 25-26 November 2004, CD523, 1-4.

[5] Meeuwse, M., van der Schaaf, J. and Schouten, J.C. (2012) Multistage Rotor-Stator Spinning Disc Reactor. AIChE Journal, 58, 247-255. https://doi.org/10.1002/aic.12586

[6] Schouveiler, L., Le Gal, P. and Chauve, M.P. (1998) Stability of a Traveling Roll System in a Rotating Disk Flow. Physics of Fluids, 10, 2695-2697. https://doi.org/10.1063/1.869793

[7] Al-Shannag, M., Herrero, J., Humphrrey, J.A.C. and Giralt, F. (2002) Effect of Radial Clearance on the Flow between Corotating Disks in Fixed Cylindrical Enclosures. Transactions of ASME. Journal of Fluids Engineering, 124, 719-727. https://doi.org/10.1115/1.1487355

[8] Hendriks, F. (2010) On Taylor Vortices and Ekman Layers in Flow-Induced Vibration of Hard Disk Drives. Microsystem Technologies, 16, 93-101. https://doi.org/10.1007/s00542-008-0765-2 
Submit or recommend next manuscript to SCIRP and we will provide best service for you:

Accepting pre-submission inquiries through Email, Facebook, LinkedIn, Twitter, etc. A wide selection of journals (inclusive of 9 subjects, more than 200 journals)

Providing 24-hour high-quality service

User-friendly online submission system

Fair and swift peer-review system

Efficient typesetting and proofreading procedure

Display of the result of downloads and visits, as well as the number of cited articles Maximum dissemination of your research work

Submit your manuscript at: http://papersubmission.scirp.org/

Or contact wjm@scirp.org 